\title{
Organ donor management in Canada: recommendations of the forum on Medical Management to Optimize Donor Organ Potential
}

\author{
Sam D. Shemie, Heather Ross, Joe Pagliarello, Andrew J. Baker, Paul D. Greig, Tracy Brand, Sandra \\ Cockfield, Shaf Keshavjee, Peter Nickerson, Vivek Rao, Cameron Guest, Kimberly Young, \\ Christopher Doig; on behalf of the Pediatric Recommendations Group
}

I n collaboration with the Canadian Critical Care Society, the Canadian Association of Transplantation and the Canadian Society of Transplantation, the Canadian Council for Donation and Transplantation (CCDT) sponsored a forum entitled "Medical Management to Optimize Donor Organ Potential," 23-25 Feb. 2004, to develop guidelines and recommendations for organ donor management in Canada. Discussions were restricted to the interval of care that begins with neurological determination of death (NDD), commonly called "brain death," and consent to organ donation, and culminates in surgical organ procurement. This period presents a significant opportunity to enhance multi-organ function and improve organ utilization.

The forum was the first structured, cooperative assembly of health professionals in the fields of critical care and transplantation and can be viewed as a landmark event in Canada. End-of-life care in the intensive care unit (ICU) includes all efforts to actualize the desire and opportunity to donate organs. The evolving collaboration to establish best donor management practices in the ICU and operating room must be accompanied by efforts to ensure optimum organ utilization. In turn, improving the use of organs must be linked with improving transplant graft and patient outcomes.

\section{Forum overview}

Therapies to protect organs rely on expert clinical management to increase the number of eligible donors and optimize organ function for the purposes of transplantation. Experts involved in this forum focused on 2 key areas:

- How to achieve optimum donor organ physiology

- How to increase the number of potential donors whose organs are suitable for donation, increase the number of organs transplanted per donor, improve graft function, graft survival and patient survival and identify and explore logistic challenges in the period from NDD to organ procurement.

This initiative did not address related challenges, such as the consent process, post-procurement organ perfusion and $\sim$ preservation or surgical retrieval team logistics.

To review and benchmark existing national and international practices, guidelines and policies related to donor organ management, including organ-protective therapies (sources included articles and reports in the basic science and clinical literature; regional, national and international

donor management guidelines; and material from related conferences and workshops)

- To develop expert consensus recommendations for organprotective therapies in the ICU and intraoperative management of the organ donor

- To develop expert consensus recommendations for the CCDT, Canadian Society of Transplantation, Canadian Critical Care Society, Canadian Association of Transplantation and other relevant organizations and groups

- To develop a mechanism to involve both critical care and transplant communities in reviewing and updating the expert consensus recommendations as therapies evolve

- To disseminate the forum findings based on current understanding of knowledge transfer in Canada

- To develop recommendations for future research in this evolving field.

The participants were health care professionals from 27 organizations, including specialists in adult and pediatric critical care, physician and surgeon specialists in adult and pediatric organ-specific transplantation, neurologists, neurosurgeons, anesthetists, emergency medicine physicians, nurses and nurse practitioners. A working group of health administrators, policymakers and donation-transplant agencies also provided input on logistic barriers and supports and knowledge transfer in support of effective medical management of organ donors.

Discussions focused on collaborative, consensus-based decision-making at a national, strategic level.

These guidelines are aimed principally at physicians (or their delegates) who are involved in the management of organ donors in the ICU and operating room setting. The following 5 areas were addressed:

- Multisystem management of multi-organ donors

- Organ-specific considerations for hearts, lungs and intraabdominal organs

- Other systemic challenges

- Potential questions for a national research agenda to optimize donor organ management

- Logistic and knowledge transfer considerations related to disseminating and implementing the forum's recommendations.

\section{Process}

Substantive background documents, provided by the steering committee in advance of the forum included comprehensive 
literature reviews and related practice surveys. During the forum, each of the 5 areas was addressed using the following process. Presentations by experts were followed by open plenary discussions. Participants then worked in small groups guided by worksheets that provided a description of current, well-accepted care in the Canadian context (based on a review of donor management guidelines in effect in Canadian health care facilities ${ }^{1}$ ); a summary of existing scientific evidence; key considerations; a summary of national and international donor management guidelines; and a list of references.

The small-group discussions focused on specific questions related to the processes of care. The Forum Recommendations Group (FRG) and the Pediatric Recommendations Group (PRG) met to review the results of the small-group and plenary discussions and develop recommendations for adults and children, which were then presented for discussion in a plenary session. Participants' input related to research questions was gathered and summarized (Appendix I). The Logistics and Knowledge Transfer (LKT) Group considered issues related to the logistics and knowledge transfer that were identified during the forum (Appendix 2).

\section{Overarching themes}

Several overarching themes were identified during discussions:

- Prospective research is needed to improve the basis for levels of evidence used by experts to develop consensus on standards of care. Most existing evidence in the area of donor management is based on retrospective, uncontrolled and observational studies.

- As a result of uncontrolled intracranial hypertension and herniation, the organ donor has a distinct pathophysiology.

- Temporal changes in multi-organ function after NDD demand flexibility in identifying the optimal time of procurement. Participants recognized that:

- resuscitation of the cardiopulmonary system benefits function of all organs

- it is important to take time in the ICU to optimize multi-organ function to improve transplant outcomes

- reversible organ dysfunction may be addressed with aggressive resuscitation and frequent re-evaluation

- once organ function is optimized, surgical procurement should be arranged emergently.

- A 4-centre Canadian review of heart and lung utilization ${ }^{2}$ identified potential deficits in the process of obtaining consent for donation of individual organs, the offering of organs and the utilization of offered organs. The forum recommends that there be no predefined demographic factor or organ dysfunction that precludes provision of consent for individual organs or the offering of organs for transplantation.

- Final decisions about transplantability rest with the individual transplant programs represented by the organ-specific transplant doctors.

- Any initiatives aimed at improving donor organ potential should be evaluated not only in terms of increases in organ utilization, but also in terms of corresponding transplant outcomes.

- ICU-transplant collaboration in this field involves ensur- ing reciprocal accountability by procurement and transplant services if available organs are not ultimately used.

\section{Multisystem management of the multi-organ donor}

Standing orders for donor management are summarized in Appendix 3.

\section{Systemic arterial hypertension related to intracranial pressure}

\section{Recommendation 1.1: Thresholds and preferred therapy}

We recommend that arterial hypertension after neurological determination of death (NDD) be treated according to the following:

Thresholds:

- Systolic blood pressure > $160 \mathrm{~mm} \mathrm{Hg}$ and/or

- Mean arterial pressure $>90 \mathrm{~mm} \mathrm{Hg}$

Preferred therapy:

- Nitroprusside, $0.5-5.0 \mu \mathrm{g} / \mathrm{kg}$ per minute and/or

- Esmolol, $100-500 \mu \mathrm{g} / \mathrm{kg}$ bolus followed by $100-300 \mu \mathrm{g} / \mathrm{kg}$ per minute

Infusions should be titrated until the desired clinical effect is achieved.

\section{Existing Canadian practice}

Significant variation in practice.

\section{Key considerations}

- There is a need to distinguish between acute intracranial pressure-related autonomic storm and arterial hypertension that may occur during herniation but before NDD. This period of care was not considered by this forum.

- Given evolving changes and risk of deterioration in cardiovascular function after NDD, short-acting agents are preferable.

- Alternative agents include:

- nitroglycerin (e.g., to reduce the potential risk of coronary steal compared with nitroprusside)

- labetolol is more commonly available and used in clinical practice than esmolol; however, there are concerns regarding its prolonged biologic half-life (4-6 h).

- Hypertension in the setting of vasopressor use or inotropic support is an indication for decreasing support rather than initiating antihypertensives.

\section{Cardiovascular performance, monitoring and hemodynamic support}

\section{Overall considerations}

The deterioration of cardiovascular function associated with intracranial hypertension, characterized by the sympathetic storm resulting in neurogenic myocardial dysfunction ${ }^{3}$ and 
intense vasoconstriction followed by sympathetic depletion, and vasodilatation ${ }^{4}$ will vary with

- Rapidity of rise of intracranial pressure ${ }^{5}$

- Time after herniation

- Etiology of brain injury (e.g., traumatic myocardial contusion, ischemia after cardiac arrest or shock, hypoxemia).

It is recognized that intensivists titrate cardiovascular therapy to clinical, biochemical and hemodynamic end points that ensure restoration of intravascular volume status without hypervolemia and provide appropriate support of the myocardium and vascular system to ensure optimal cardiac output for organ perfusion.

The initiation of cardiovascular support assumes that patients will have been restored to normovolemia.

Evaluation of cardiocirculatory status requires assessment of multiple variables. No single measurement or one value in isolation should determine therapy.

Escalation of support should be accompanied by escalation of hemodynamic monitoring.

Although these targets serve as guidelines for therapy, rigid adherence to numbers should be balanced by the overall evaluation of cardiovascular status by experienced clinicians.

Cardiovascular support should be based on rational physiology. Pure vasopressors (vasopressin, phenylephrine) should be distinguished from vasopressors with beta-agonist inotropic action (norepinephrine, epinephrine). Beta-agonist therapy should be used with caution in potential heart donors, given concerns about myocardial adenosine triphosphate (ATP) depletion and downregulation of beta-receptors. ${ }^{6}$ If the heart is being considered for donation, dopamine or its equivalent should not be administered at a rate higher than Io $\mu \mathrm{g} / \mathrm{kg}$ per minute.

\section{Existing Canadian practice}

The following were identified as areas of well-accepted practice and endorsed a priori:

- Standard monitoring: arterial line, central venous line, I2lead electrocardiogram

- Hemodynamic targets include:

- mean arterial pressure $\geq 70 \mathrm{~mm} \mathrm{Hg}$

- systolic blood pressure $\geq 100 \mathrm{~mm} \mathrm{Hg}$

- heart rate 60-I20 beats per minute

central venous pressure 6-Io mm Hg (normovolemia).

- Standard inotropic support includes dopamine $\leq$ Io $\mu \mathrm{g} / \mathrm{kg}$ per minute (or equivalent).

\section{Recommendation 2.1: Monitoring of central or mixed venous oxygen saturation}

Monitoring of mixed venous oxygen saturation is indicated in patients with ongoing hemodynamic instability. Hemodynamic therapy should be tailored to reach a target of $\geq 60 \%$ saturation.

\section{Existing Canadian practice}

Data not available.

\section{Key considerations}

- Serial trends are more useful than single measurements.

- Mixed venous oximetry may be determined by sampling intermittently from the pulmonary artery or continuously via oximetric catheters.

- Tissue oxygen extraction has not been well studied in patients declared neurologically dead. Low values may reflect reduced oxygen delivery; however, high values in the face of arrested neurological function or arrested brain circulation may not be interpreted reliably.

- Central venous oximetry is not well studied in patients declared neurologically dead.

\section{Recommendation 2.2: Lactate monitoring}

We recommend that serial lactate measurements be performed in all patients. In the presence of elevated or rising lactate levels, we recommend investigations to determine etiology.

\section{Existing Canadian practice}

Data not available.

\section{Key consideration}

Decreasing lactate levels reflect improvements in oxygen delivery.

\section{Recommendation 2.3: Indications for pulmonary artery catheterization}

We recommend pulmonary artery catheterization (PAC) when:

- 2-dimensional echocardiographic assessment of ejection fraction is $\leq 40 \%$ or

- Patients require

- dopamine (> $\mathrm{Io} \mu \mathrm{g} / \mathrm{kg}$ per minute) or equivalent

- vasopressor support (where vasopressin is not included as part of hormone therapy) and/or

- an escalation of supports.

PAC hemodynamic targets are: pulmonary capillary wedge pressure (PCWP) 6-Io $\mathrm{mm} \mathrm{Hg}$; cardiac index $>2.4 \mathrm{~L} /$ minute- $^{2}$; systemic vascular resistance (SVR): 800-I200 dynes/s- $\mathrm{cm}^{5}$; left ventricular stroke work index (LVSWI) $>15 \mathrm{~g} / \mathrm{kg}$-minute.

\section{Existing Canadian practice}

Significant variation in practice.

\section{Key considerations}

- "Vasopressor" refers to a vasoconstricting agent.

- Although use of PAC in adult intensive care practice is decreasing, the organ donor has a distinct pathophysiology.

- Justifications for PAC are not limited to the precise titration of hemodynamic support but are also required for the evaluation of suitability for heart and lung transplantation. ${ }^{7}$

- Two-dimensional echocardiography is primarily indicated to evaluate cardiac function and the suitability of the heart 
for transplantation. The role of single or serial echocardiography in the assessment of cardiac function as a guide to hemodynamic therapy in the unstable organ donor is not well established.

\section{Recommendation 2.4: First-line agents for hemodynamic support - vasopressin}

We recommend that vasopressin be used for hemodynamic support when vasopressor agents are indicated. The maximum dose should be $2.4 \mathrm{U} / \mathrm{h}$ (0.04 U/minute).

\section{Existing Canadian practice}

Significant variation in practice.

\section{Key considerations}

- Vasopressin is a special agent because it can be used in a variety of applications, i.e., hemodynamic vasopressor support, diabetes insipidus therapy and hormonal therapy.

- Standardization of dosing units is required.

- Weaning of catecholamine support is the first approach to treating arterial hypertension in patients on vasopressin.

\section{Recommendation 2.5: Second-line agents for hemodynamic support - norepinephrine, epinephrine and phenylephrine}

We recommend the use of norepinephrine, epinephrine and/or phenylephrine for hemodynamic support. Doses should be titrated to achieve clinical effect, with no predetermined upper limit.

\section{Existing Canadian practice}

Significant variation in practice.

\section{Key consideration}

Escalation of doses of catecholamines should be guided by PAC data. Doses beyond $0.2 \mu \mathrm{g} / \mathrm{kg}$ per minute of any of these agents should be used with caution.

\section{Glycemia and nutrition}

\section{Recommendation 3.1: Glycemic control}

We recommend glucose control with insulin infusions titrated to achieve a blood glucose level of $4-8 \mathrm{mmol} / \mathrm{L}$.

\section{Existing Canadian practice}

Significant variation in practice.

\section{Key consideration}

The use of insulin should not be misinterpreted as a form of insulin dependence that might preclude islet cell transplantation. If clarification is required, hemoglobin ( $\mathrm{HgB}) \mathrm{A}_{1 \mathrm{C}}$ levels should be measured under these circumstances.

\section{Recommendation 3.2: Nutrition}

- Intravenous (IV) dextrose infusions should be given routinely.

- Routine enteral feeding should be initiated or continued as tolerated and discontinued on call to the operating room.

- Parenteral nutrition should not be initiated; however, where it has been initiated, it should be continued.

\section{Existing Canadian practice}

Data not available.

Key considerations

None.

\section{Diabetes insipidus and hypernatremia}

\section{Existing Canadian practice}

The following were identified as areas of well-accepted practice and endorsed a priori:

- Serum sodium target range is $130-150 \mathrm{mmol} / \mathrm{L}$.

- Urine output target range is $0.5-3 \mathrm{~mL} / \mathrm{kg}$ per $\mathrm{h}$ (in adults and children).

- Diabetes insipidus can be defined as urine ouptut $>4 \mathrm{~mL} / \mathrm{kg}$ per $\mathrm{h}$ in adults and children

- Associated with rising serum sodium ( $\geq \mathrm{I} 45 \mathrm{mmol} / \mathrm{L})$

- Associated with rising serum osmolarity ( $\geq 300$ mosM) and decreasing urine osmolarity ( $\leq 200$ mosM).

- Doses of I-desamino-D-arginine vasopressin (DDAVP) for diabetes insipidus

- adults: I-4 $\mu$ g IV then I-2 $\mu$ g IV every $6 \mathrm{~h}$ to achieve urine output $<4 \mathrm{~mL} / \mathrm{kg} / \mathrm{h}$

- children: $0.25-\mathrm{I} \mu \mathrm{g}$ IV every $6 \mathrm{~h}$ to achieve urine output $<4 \mathrm{~mL} / \mathrm{kg} / \mathrm{h}$.

\section{Recommendation 4.1: Diabetes insipidus}

- Diabetes insipidus in isolation can be treated with continuous IV vasopressin infusion ( $\leq 2.4 \mathrm{U} / \mathrm{h}$ ) or intermittent IV DDAVP

- Under the following circumstances, vasopressin infusion should be the first choice:

- hemodynamic support with vasospressin required

- combination hormonal therapy implemented

- If required, DDAVP should be used as a supplement to vasopressin

- DDAVP does not have to be discontinued before proceeding to the operating room.

\section{Key consideration}

DDAVP is an analog of AVP with a relatively pure antidiuretic effect and negligible vasopressor activity. ${ }^{8}$ Upper limits of DDAVP dosing are empirical. There is no clear upper limit for DDAVP dose, as it should be titrated to achieve the desired effect of reducing urine output. 


\section{Recommendation 4.2: Hypernatremia}

We recommend that hypernatremia be treated in all donors if serum sodium levels are greater than $150 \mathrm{mmol} / \mathrm{L}$.

\section{Key consideration}

Hypernatremia (serum sodium > $155 \mathrm{mmol} / \mathrm{L}$ ) is independently associated with hepatic dysfunction and graft loss. ${ }^{9}$ In addition to sodium control, calcium, phosphate, potassium and magnesium levels should be empirically normalized.

\section{Combined hormonal therapy}

\section{Recommendation 5.1: Thyroid hormone, vasopressin and methylprednisolone}

Combined hormonal therapy is defined as administration of

- Thyroid hormone (tetraiodothyronine or T4), $20 \mu \mathrm{g} \mathrm{IV} \mathrm{bo-}$ lus followed by ro $\mu \mathrm{g} / \mathrm{h}$ IV infusion

- Vasopressin, I U IV bolus followed by $2.4 \mathrm{U} / \mathrm{h}$ IV infusion

- Methylprednisolone, $15 \mathrm{mg} / \mathrm{kg}$ IV every $24 \mathrm{~h}$.

We recommend that combined hormonal therapy be used in donors with an ejection fraction $\leq 40 \%$, based on 2-dimensional echocardiographic assessment, or hemodynamic instability. Consideration should be given to its use in all donors.

\section{Existing Canadian practice}

Significant variation in practice.

\section{Key considerations}

- Hemodynamic instability includes shock unresponsive to attempts to restore normovolemia and requiring vasoactive support (dopamine > Io $\mu \mathrm{g} /$ minute) or any vasopressor.

- Weight of currently available evidence in a large retrospective cohort study by the United Network for Organ Sharing $(\mathrm{UNOS})^{10}$ in the United States suggests a substantial benefit of triple hormone therapy with minimal risk. A multivariate logistic regression analysis of 18726 brain-dead donors showed significant increases in kidney, liver and heart utilization from donors receiving 3 hormonal therapies. Significant improvements in I-year kidney graft survival and heart transplant patient survival were also demonstrated. A prospective randomized trial has not been performed.

- As peripheral tissue conversion of $\mathrm{T}_{4}$ into triiodothryonine (T3) may be impaired in organ donors and in those on corticosteroids, intravenous $\mathrm{T}_{3}$ may be preferred but is not commercially available in Canada at this time. Intravenous $\mathrm{T}_{4}$ and enteral $\mathrm{T}_{3}$ are currently available.

- In the UNOS patients receiving hormone therapy, ${ }^{10} \mathrm{~T} 4$ was used in $93 \%$ and $\mathrm{T}_{3}$ in $6.9 \%$ of cases, but numbers were insufficient to discriminate any benefit of $\mathrm{T}_{3}$ over $\mathrm{T}_{4}$.

- When administered by continuous infusion, the bioavailability of intravenous $\mathrm{T}_{4}$ may be affected by its stability in solution and potential adherence to plastic tubing resulting from its hydrophobic nature. The quantitative impact of this pharmacologic concern is unclear. Alternatively, intra- venous $\mathrm{T}_{4}$ may be given as follows: Ioo ug IV bolus followed by 50 ug IV qI2h. Should future data show a benefit of intravenous $\mathrm{T}_{3}$ over $\mathrm{T}_{4}$, the Canadian Health Protection Branch should be lobbied to make intravenous $\mathrm{T}_{3}$ therapy available in Canada for this indication.

- Absorption and pharmacokinetic data on enteral $\mathrm{T}_{3}$ in organ donors is required before its use can be recommended.

- Vasopressin should be initiated at a fixed rate. If arterial hypertension ensues, catecholamines should be weaned before decreasing the vasopressin infusion rate.

\section{Recommendation 5.2: Corticosteroids and lung protection}

We recommend that methylprednisolone be administered intravenously to all donors at a dose of $\mathrm{I} 5 \mathrm{mg} / \mathrm{kg}$ every $24 \mathrm{~h}$; this is to be initiated following NDD.

\section{Existing Canadian practice}

Methylprednisolone is administered to potential lung donors at the dose of $15 \mathrm{mg} / \mathrm{kg}$ IV (maximum dose I g).

\section{Key consideration}

Corticosteroid therapy is currently indicated as the immune modulating therapy for potential lung donors ${ }^{11}$ but protocols for administration of corticosteroids are non-uniform.

\section{Transfusion thresholds}

\section{Recommendation 6.1: Acceptable targets for hemoglobin, platelets and coagulation parameters}

- A target hemoglobin level of $90-100 \mathrm{~g} / \mathrm{L}$ is most appropriate to optimize cardiopulmonary function in the face of hemodynamic instability. A level of $70 \mathrm{~g} / \mathrm{L}$ is the lowest acceptable limit for management of stable donors in the ICU.

- There are no defined targets for platelet concentration, international normalized ratio or partial thromboplastin time. Platelet or plasma factor replacement is indicated for clinical bleeding only.

- Blood drawing for donor serology and tissue typing should occur before transfusions to minimize the risk of false results related to hemodilution.

- No special transfusion precautions are required in organ donors.

\section{Existing Canadian practice}

Significant variation in practice.

\section{Key considerations}

- Red blood cell transfusions can be associated with inflammatory activation related to the age of the blood.

- Consider the crystalloid sparing effect of red cell transfusions in potential lung donors with alveolar-capillary leak.

- Invasive procedures associated with bleeding risk may re- 
quire correction of thrombocytopenia and coagulation status.

- Intraoperative transfusion of red blood cells, platelets and plasma factors by anesthetists and the transplant team should be individually tailored.

- In Canada, blood is routinely depleted of leukocytes and the risk of transmission of cytomegalovirus (CMV) is negligible. It is not necessary to give CMV-negative blood to CMV-negative donors.

\section{Invasive bacterial infections}

\section{Recommendation 7.1: Daily blood cultures}

- An initial baseline blood culture should be carried out for all donors and repeated after $24 \mathrm{~h}$ and on an as-needed basis.

- Positive blood cultures or confirmed infections are not contraindications to organ donation

- Antibiotic therapy should be initiated in cases of proven or presumed infection. Duration of therapy depends on the virulence of the organism and decisions should be made in consultation with the transplant team and infectious disease services.

- No minimum duration of therapy before organ procurement can be defined at this time.

\section{Existing Canadian practice}

Standard care includes urine and endothracheal tube aspirate cultures.

\section{Key considerations}

None.

\section{Recommendation 7.2: Broad-spectrum antibiotics}

- Empiric broad-spectrum antibiotics are not indicated during ICU care of the organ donor.

- Decisions regarding use of perioperative antibiotics should be at the discretion of the surgical team.

\section{Existing Canadian practice}

Data not available.

Key considerations

None.

\section{Organ-specific considerations: heart, lungs and intra-abdominal organs}

\section{Heart}

\section{Existing Canadian practice}

The following was identified as well-accepted practice and endorsed a priori.
- Potential cardiac donors undergo routine screening by electrocardiogram and 2-dimensional echocardiography.

\section{Recommendation 8.1: Initial evaluation of cardiac function}

If the initial evaluation of cardiac function reveals an ejection fraction of $\leq 40 \%$ based on 2-dimensional echocardiographic assessment, the optimum course is to insert a pulmonary artery catheter and institute therapy to achieve the PAC hemodynamic targets listed in Recommendation 2.3.

\section{Key considerations}

- Achieving PAC targets has been linked to favourable transplant outcomes. ${ }^{7,12}$

- Initial echocardiography for heart donor evaluation should be performed only after hemodynamic resuscitation. Repeat echocardiography should be considered after $6 \mathrm{~h}$. There is a need for prospective study of the utility of serial echocardiography.

- Justifications for PAC are not limited to precision of hemodynamic support, but are also required for the evaluation of suitability for heart and lung transplantation. Transplant decision-making should reflect these recommendations. An abnormal 2-dimensional echocardiogram followed by favourable hemodynamic data by PAC is an acceptable assessment and does not require follow-up echocardiography.

- PAC is recommended when appropriate technical and interpretive expertise is available.

\section{Recommendation 8.2: Troponin levels}

We recommend the measurement of troponin (either I or T) levels every $\mathrm{I} 2 \mathrm{~h}$ as standard monitoring to obtain both clinical and prognostic information.

\section{Key consideration}

Troponin levels should not be used in isolation as the basis to reject hearts for transplantation.

\section{Recommendation 8.3: Coronary angiography}

- We recommend that the following donor characteristics be indications for coronary angiography:

- male $>55$ years of age or female $>60$ years

- male $>40$ years of age or female $>45$ years in the presence of 2 risk factors (see "Key considerations")

- presence of 3 or more risk factors at any age

- history of cocaine use.

- If the hospital has angiography facilities and indications for angiography are present, an angiogram should always be performed to document coronary anatomy to assist in decision-making.

- There should be no absolute threshold for coronary luminal obstruction; decisions should be made in the context of the recipient status, heart function and the potential to intervene through coronary artery bypass grafting or percutaneous coronary intervention (e.g., stent). 
- The inability to perform an angiogram should not preclude transplantation. Where coronary angiography is not available, cardiac donor organ suitability should still be considered in the following circumstances:

- ejection fraction of $>40 \%$ on 2 -dimensional echocardiographic assessment or

- hemodynamic stability or

- surgical inspection at the time of procurement.

- The option of patient transfer to a procurement hospital with angiogram capabilities should be considered on a case-by-case basis with full consent of the donor family.

\section{Key considerations}

- Cardiovascular risk factors for coronary artery disease that have an impact on transplant outcomes include ${ }^{13,14}$

- smoking

- hypertension

- diabetes

- hyperlipidemia

- body mass index $>32$

- family history of the disease

- prior history of coronary artery disease

- ischemia on electrocardiogram

- anterolateral regional wall motion abnormalities on echocardiogram

- 2-dimensional echocardiographic assessment of ejection fraction of $\leq 40 \%$.

- To minimize the risk of contrast nephropathy:

- normovolemia should be ensured

- N-acetylcysteine should be given prophylactically at doses of 600-I000 mg enterally twice daily, with the first dose administered as soon as it is recognized that angiography is indicated. Alternatively $\mathrm{N}$-acetylcysteine may be administered intravenously at $150 \mathrm{mg} / \mathrm{kg}$ in $500 \mathrm{~mL}$ normal saline over 30 minutes immediately before contrast agent, followed by $50 \mathrm{mg} / \mathrm{kg}$ in $500 \mathrm{~mL}$ of normal saline over $4 \mathrm{~h}$.

- angiograms should be performed with a low-risk radiocontrast agent (non-ionic, iso-osmolar), using minimum radiocontrast volume and without a ventriculogram.

\section{Lungs}

For recommendations related to corticosteroids and lung protection, see Recommendation 5.2.

\section{Existing Canadian practice}

The following were identified as areas of well-accepted practice and endorsed a priori:

- Pulse oximetry, serial arterial blood gas monitoring, endotracheal tube suctioning, chest radiography, bronchoscopy and bronchoalveolar lavage.

- Mechanical ventilation with the following targets:

- fraction of inspired oxygen $\left(\mathrm{FIO}_{2}\right)$ titrated to keep oxygen saturation $\geq 95 \%$ and partial pressure of arterial oxygen $\left(\mathrm{PaO}_{2}\right) \geq 80 \mathrm{~mm} \mathrm{Hg}$
- pH: 7.35-7.45, $\mathrm{PaCO}_{2}: 35-45 \mathrm{~mm} \mathrm{Hg}$

- Positive end expiratory pressure (PEEP): $5 \mathrm{~cm} \mathrm{H}_{2} \mathrm{O}$.

\section{Recommendation 9.1: Oxygenation impairment}

In cases where the partial pressure of arterial oxygen/fraction of inspired oxygen $(\mathrm{P} / \mathrm{F})$ ratio is $<300$, we recommend that

- Positional rotation therapy should be routine and defined as rotation to a lateral position every $2 \mathrm{~h}$.

- Routine suctioning and physiotherapy should be standard care.

- A positive end expiratory pressure (PEEP) of $5 \mathrm{~cm} \mathrm{H}_{2} \mathrm{O}$ is recommended, but periodic increases of PEEP up to $15 \mathrm{~cm}$ $\mathrm{H}_{2} \mathrm{O}$ is an acceptable form of alveolar recruitment.

- Sustained inflations (peak inspiratory pressure of $30 \mathrm{~cm}$ $\mathrm{H}_{2} \mathrm{O}$ for $30-60 \mathrm{~s}$ ) is an acceptable form of alveolar recruitment.

- Diuresis to normovolemia should be initiated when indicated.

\section{Key considerations}

- Evaluation of $\mathrm{P} / \mathrm{F}$ ratio is performed when PEEP is $5 \mathrm{~cm}$ $\mathrm{H}_{2} \mathrm{O}$ and $\mathrm{FIO}_{2}$ is I.o.

- Recruitment maneuvers should be used periodically in all donors regardless of $\mathrm{P} / \mathrm{F}$ ratio and should continue through the intraoperative period.

- Prone positioning is not recommended for either adult or pediatric donors.

\section{Recommendation 9.2: Lower limits for the P/F ratio}

- There should be no predefined lower limit for the P/F ratio that precludes transplantation.

- Timing of evaluation, temporal changes, response to alveolar recruitment and recipient status should be considered.

- In cases of unilateral lung injury, pulmonary venous $\mathrm{PO}_{2}$ during intraoperative assessment is required to evaluate contralateral lung function reliably.

\section{Key considerations}

None.

\section{Recommendation 9.3: Optimum targets for tidal volume and peak inspiratory pressure}

We recommend that:

- Tidal volume be 8 -Io $\mathrm{mL} / \mathrm{kg}$.

- The upper limit of peak inspiratory pressure be $\leq 30 \mathrm{~cm}$ $\mathrm{H}_{2} \mathrm{O}$.

\section{Key consideration}

Lung protective strategies are currently used in patients with, or at risk of, acute respiratory distress syndrome, where pressure-limited ventilation is defined by a peak inspiratory pressure $<35 \mathrm{~cm} \mathrm{H}_{2} \mathrm{O}$ and tidal volume of $6-8 \mathrm{~mL} / \mathrm{kg}$. ${ }^{15}$ Benefits of these strategies apply to acute respiratory distress syndrome patients and corresponding data for organ donors are not available. 


\section{Recommendation 9.4: Bronchoscopy and antimicrobial therapy}

- Bronchoscopy can be performed by the local hospital expert and reported to the responsible transplant surgeon.

- Antimicrobial therapy should be based on the results of Gram staining or culture or suspected or confirmed bronchopneumonia.

- Empiric broad-spectrum antibiotics are not routinely indicated, but may be used in donors at high risk of bronchopneumonia.

- Length of stay in the ICU is not an independent indication for antimicrobial therapy.

\section{Key considerations}

- Technology should be developed to enable:

- remote review of bronchoscopy and chest radiographic images

- 3-way communication among ICUs, organ procurement organizations and transplant surgeons

- Nephrotoxic antimicrobials should be avoided when possible.

\section{Liver}

\section{Existing Canadian practice}

The following was identified as an area of well-accepted practice and endorsed a priori:

- Potential liver donors are assessed for

- history of jaundice, hepatitis, excessive alcohol ingestion

- hepatic aspartate aminotransferase (AST), alanine aminotransferase (ALT), bilirubin (direct and indirect where available) and international normalized ratio (INR) or prothrombin time (PT), repeated every $6 \mathrm{~h}$

- serum electrolytes, creatinine, urea hepatitis B surface antigen (HBsAg),

hepatitis B core antibody (HBcAb), hepatitis C virus antibody (HCVAb).

\section{Recommendation 10.1: Upper limits of hepatic aspartate aminotransferase (AST) and alanine aminotransferase (ALT)}

We recommend that there be no upper limits for hepatic AST and ALT that preclude liver transplantability. All livers should be offered; decisions related to transplantability depend on organ status, trends in liver function over time and recipient status.

\section{Key considerations}

None.

\section{Recommendation 10.2: Hepatic ultrasound}

We recommend that there be no requirement for prospective liver donors to undergo hepatic ultrasound.
Key considerations

None.

\section{Recommendation 10.3: Indications for liver biopsy}

We recommend the following indications for ultrasoundguided percutaneous liver biopsy in the ICU before procurement, in consultation with the liver transplant team, to enable decisions about transplantability:

- Weight $>$ Ioo kg or body mass index $>30$ or HCVAb positive donor and

- Distant procurement, i.e., when a procurement team is not immediately available.

Intraoperative biopsy by the liver retrieval team is recommended in all other instances where liver biopsy is indicated.

If the biopsy cannot be done in the ICU and indications for biopsy exist, the liver should be offered and transplantation should be at the discretion of the liver transplant team.

\section{Key considerations}

None.

\section{Kidney}

\section{Existing Canadian practice}

The following were identified as areas of well-accepted practice and endorsed a priori:

- A normal creatinine clearance rate $(>80 \mathrm{~mL} /$ minute/ I.73 $\mathrm{m}^{2}$ ) defines the optimum function threshold for transplantation. However, an abnormal serum creatinine level or calculated creatinine clearance rate in a donor does not necessarily preclude use of the donor kidneys.

- Urinalysis is essential to rule out kidney abnormalities.

- Creatinine and serum urea (blood urea nitrogen) are measured every $6 \mathrm{~h}$.

\section{Recommendation 11.1: Creatinine clearance rate}

We recommend that measurement of creatinine clearance rate be based on the Cockroft-Gault equation; urine collection to measure creatinine clearance is not indicated.

\section{Key consideration}

There is no absolute contraindication to kidney donation based on a serum creatinine level or creatinine clearance rate alone.

\section{Recommendation 11.2: Renal ultrasound}

We recommend that renal ultrasound be performed on a case-by-case basis, taking into account factors such as a history of renal disease.

\section{Key consideration}

In general, there are no firm indications for renal ultrasound; this investigation tends to yield little information. 


\section{Recommendation 11.3: Indications for kidney biopsy}

We recommend that the following variables be considered in determining the need for intraoperative kidney biopsy at the time of procurement to enable decisions about transplantability:

- Age $>65$ years or a younger age with a history of any of the following:

- creatinine level > $33 \mu \mathrm{mol} / \mathrm{L}$

- hypertension

- diabetes

- abnormal urinalysis.

\section{Key consideration}

Histologic evaluation and assessing for glomerulosclerosis or vasculopathy or both is required before excluding kidneys. The biopsy should be performed intraoperatively at the time of procurement, rather than in the ICU.

\section{Other systemic challenges}

\section{Optimum time for organ procurement and deci- sions regarding transplantability}

\section{Recommendation 12.1: Optimum time for organ procurement}

It is important to take the necessary time in the ICU to optimize multi-organ function to improve transplant outcomes. Reversible organ dysfunction can be improved with resuscitation and re-evaluation. The treatment period can range from I 2 to $24 \mathrm{~h}$ and should be accompanied by frequent re-evaluation to demonstrate improvement in organ function toward defined targets. Once organ function is optimized, surgical procurement procedures should be arranged emergently.

\section{Existing Canadian practice}

In general, after neurological death has been declared and consent to organ donation has been given, efforts are made to complete donation logistics and initiate procurement as quickly as possible.

\section{Key considerations}

- The existing paradigm of care should be adjusted in view of the following situations that may be correctable or may benefit from resuscitation and re-evaluation:

- myocardial or cardiovascular dysfunction

- oxygenation impairment related to potentially reversible lung injury

- invasive bacterial infections

- hypernatremia

- temporal trends in AST and ALT

- temporal trends in creatinine level

- any other potentially treatable situation.

- Extending the interval of donor care in the ICU to optimize transplant outcomes should be factored into donation consent discussions and should be consistent with the wishes of the family or surrogate decision-maker.

\section{Recommendation 12.2: Decisions regarding transplantability}

We recommend that there be no predefined demographic factor or organ dysfunction thresholds that preclude providing consent for individual organs or offering organs for transplantation and that:

- Consent be requested for all organs

- Within the context of existing legal and regulatory frameworks, all organs be offered

- Ultimate decisions about transplantability rest with the individual transplant programs represented by the organspecific transplant doctors.

\section{Existing Canadian practice}

Significant variation in practice.

\section{Key considerations}

- Accountability for nonutilization of organs is required from procurement and transplant services. The limited data currently provided to the Canadian Organ Replacement Register recording reasons for nonutilization of organs are inadequate.

- Utilization of organs should be linked with corresponding transplant graft and patient outcomes.

- Issues related to transmissible viruses or malignancy should comply with existing Canadian standards and guidelines. ${ }^{16}$

\section{Pediatric age-related adjustments}

\section{Recommendation 13: Pediatric age-related adjustments}

We recommend that Recommendations I-I2 be applied to infants, children and adolescents with the following qualifications. (The numbers are those of the corresponding adult recommendations.)

\section{Overarching}

- The pediatric organ donor is defined as:

- newborn to I8 years and

- care provided within a pediatric ICU.

- Dosing recommendations apply to children $\leq 60 \mathrm{~kg}$; for children over $60 \mathrm{~kg}$, adult dosing should apply.

\section{1: Systemic arterial hypertension related to intracranial pressure}

Thresholds for treating arterial hypertension after NDD are:
Newborns -3 months
$>3$-I2 months
$>90 / 60 \mathrm{~mm} \mathrm{Hg}$
I-I2 years
$>$ IIO/70 $\mathrm{mm} \mathrm{Hg}$
$>\mathrm{I} 2 \mathrm{I}$ 18 years
$>$ I $40 / 90 \mathrm{~mm} \mathrm{Hg}$ 


\section{Cardiovascular performance, monitoring and hemo- dynamic support}

- Experienced pediatric intensive care practitioners adjust therapies to general, rather than specific, age-related targets. For information purposes, a guide to age-related norms for heart rate and blood pressure is provided under "Key considerations" below.

\section{1: Monitoring of central or mixed venous oxygen saturation}

- Central venous oximetry is currently used in many Canadian pediatric ICUs as a monitoring technique in patients with hemodynamic instability and is recommended for the pediatric donor. Therapy should be titrated to a central venous oxygen saturation of $\geq 60 \%$.

\section{3: Indications for PAC}

- The use of PAC is limited in pediatric ICU practice and is not routinely recommended in pediatric donors. PAC may be used at the discretion of the pediatric ICU practitioner who is experienced with its application and interpretation.

- Serial echocardiography is the recommended method for re-evaluating myocardial function for transplantation. Its role as a potential tool to guide hemodynamic therapy should be individually tailored.

\section{4: First-line agents for hemodynamic support - vasopressin}

- The pediatric dose range for vasopressin is $0.0003^{-}$ $0.0007 \mathrm{U} / \mathrm{kg}$ per minute $(0.3-0.7 \mathrm{mU} / \mathrm{kg}$ minute) to a maximum dose of $2.4 \mathrm{U} / \mathrm{h}$.

\section{5: Second-line agents for hemodynamic support -} Norepinephrine, epinephrine and phenylephrine

- In the absence of PAC data, hemodynamic therapy should be titrated to clinical and biochemical targets.

\section{1: Diabetes insipidus}

- The pediatric dose range for vasopressin is $0.0003^{-}$ $0.0007 \mathrm{U} / \mathrm{kg}$ per minute $\left(0.3^{-}-0.7 \mathrm{mU} / \mathrm{kg}\right.$ per minute) to a maximum dose of $2.4 \mathrm{U} / \mathrm{h}$.

\section{1: Thyroid hormone, vasopressin and methylprednisolone}

- The pediatric dose range for vasopressin is $0.0003^{-}$ $0.0007 \mathrm{U} / \mathrm{kg}$ per minute (0.3-0.7 mU/kg per minute) to a maximum dose of $2.4 \mathrm{U} / \mathrm{h}$.

- Intravenous $\mathrm{T}_{4}$ : The precise dose range for $\mathrm{IV} \mathrm{T}_{4}$ infusions is not known and its biological effect when given by infusion may be affected by its stability in solution and potential adherence to plastic tubing resulting from its hy- drophobic nature. Adult practitioners have used up to 300-500 $\mu \mathrm{g}$ IV bolus for potential donors and this is standard dosing for myxedema coma. Given the wide dosing range cited in the literature for IV $\mathrm{T}_{4}$ and the low risk of toxicity for this current indication, the adult range -20 $\mu \mathrm{g}$ IV bolus followed by Io $\mu \mathrm{g} / \mathrm{h}$ IV infusion - is also recommended for children. ${ }^{17}$ Alternatively, intravenous $\mathrm{T}_{4}$ may be given as follows: 50-100 $\mu \mathrm{g}$ IV bolus followed by $25-50$ ug iv qI2h.

\section{1: Initial evaluation of cardiac function}

- Serial echocardiography is recommended to evaluate myocardial function for the purposes of transplantation. The initial echocardiogram should be performed only after stabilization with adequate volume resuscitation.

- The echocardiogram should be repeated every 6-I2 h under the following conditions:

- initial 2 dimensional echocardiogram reveals an ejection fraction $\leq 40 \%$ or

- escalation of supports as defined by dopamine $>$ Io $\mu \mathrm{g} / \mathrm{kg}$ per minute, the use of vasopressor agents or both.

\section{1: Creatinine clearance rate}

- For children $>\mathrm{I}$ year of age, a normal creatinine clearance rate is $>80 \mathrm{~mL} /$ minute $/ \mathrm{I} .73 \mathrm{~m}^{2}$, as estimated by the Schwartz formula. ${ }^{18}$

\section{3: Indications for kidney biopsy}

- Creatinine level higher than normal for age.

Key considerations

See Table I.

\begin{tabular}{lccc}
\multicolumn{4}{l}{ Table 1: Age-related norms for heart rate and blood pressure } \\
\hline Age & $\begin{array}{c}\text { Heart Rate } \\
\text { beats/min }\end{array}$ & $\begin{array}{c}\text { Systolic BP } \\
(\mathrm{mm} \mathrm{Hg})\end{array}$ & $\begin{array}{c}\text { Diastolic BP } \\
(\mathrm{mm} \mathrm{Hg})\end{array}$ \\
\hline 0-3 mo & $100-150$ & $65-85$ & $45-55$ \\
\hline $3-6 \mathrm{mo}$ & $90-120$ & $70-90$ & $50-65$ \\
\hline $6-12 \mathrm{mo}$ & $80-120$ & $80-100$ & $55-65$ \\
$1-3 \mathrm{yr}$ & $70-110$ & $90-105$ & $55-70$ \\
$3-6 \mathrm{yr}$ & $65-110$ & $95-110$ & $60-75$ \\
\hline $6-12 \mathrm{yr}$ & $60-95$ & $100-120$ & $60-75$ \\
$>12 \mathrm{yr}$ & $55-85$ & $110-135$ & $65-85$ \\
\hline
\end{tabular}

Adapted from: Mathers LH, Frankel LR. Stabilization of the Critically IIl Child. Nelson textbook of pediatrics, $17^{\text {th }}$ Edition, 2004. ${ }^{19}$

This article has been peer reviewed.

From Division of Pediatric Critical Care, Montreal Children's Hospital, McGill University Health Centre, Montréal, Que. (Shemie), Cardiac Transplant Program, Toronto General Hospital, University Health Network (Ross), GI Transplant Program, Toronto General Hospital, University Health Net- 
work (Greig), General Surgery, ICU and Organ and Tissue Donation Program, The Ottawa Hospital (Pagliarello), Trauma and Neurosurgery Intensive Care Unit, St. Michael's Hospital, University of Toronto, Toronto, Ont. (Baker), Adult Critical Care, Foothills Hospital, Calgary, Alta. (Doig), Trillium Gift of Life Network (Baker), Canadian Critical Care Society (Shemie, Pagliarello, Baker, Doig, Guest), Canadian Anesthesiologists' Society (Baker), Canadian Organ Replacement Register (Greig), Canadian Society of Transplantation (Greig, Ross, Cockfield, Keshavjee, Rao, Nickerson), Canadian Association of Transplantation (Brand, Young), Kidney Transplant Program, University of Alberta Hospital, Edmonton, Alta. (Cockfield), Toronto Lung Transplant Program, University Health Network, University of Toronto, Toronto, Ont. (Keshavjee), Immunogenetics Laboratory, University of Manitoba Health Services Centre, Winnipeg, Man. (Nickerson), Cardiac Transplant Program, University Health Network, University of Toronto, Toronto, Ont. (Rao), Department of Critical Care Medicine, Sunnybrooke and Women's College Hospital, Toronto, Ont. (Guest), Canadian Council for Donation and Transplantation (Shemie, Young, Doig), Saskatchewan Transplant Program (Brand).

See Appendix 4 for a complete list of forum participants.

Competing interests: None declared for Sam Shemie, Heather Ross, Joe Pagliarello, Andrew Baker, Tracy Brand, Sandra Cockfield, Shaf Keshavjee, Peter Nickerson, Vivek Rao, Cameron Guest, Kimberly Young or Christopher Doig. Paul Greig has received speaker's fees and travel assistance from Hoffmann La-Roche and Fujisawa Canada Inc. to attend meetings.

Acknowledgements: These recommendations have been endorsed by the Canadian Critical Care Society, the Canadian Association of Transplantation, the Canadian Society of Transplantation and the Canadian Council for Donation and Transplantation.

We acknowledge the Canadian Council for Donation and Transplantation for financial support to prepare and organize the forum; the collaboration of the Canadian Critical Care Society, the Canadian Association of Transplantation and the Canadian Society of Transplantation in holding the forum; and the process consultation provided by Strachan-Tomlinson.

\section{REFERENCES}

I. Hornby K, Shemie SD. Donor organ management: survey of guidelines and eligibility criteria. Edmonton: Canadian Council for Donation and Transplantation; 2004.

2. Hornby K, Ross H, Keshavjee S, et al. Factors contributing to non-utilization of heart and lungs after consent for donation: a Canadian multicentre study. Can J Anaesth 2006; in press.

3. Tung P, Kopelnik A, Banki N, et al. Predictors of neurocardiogenic injury after subarachnoid hemorrhage. Stroke 2004; 35(2):548-51.

4. Novitzky D. Detrimental effects of brain death on the potential organ donor. Transplant Proc 1997;29:3770-2.

5. Shivalkar B, Van Loon J, Wieland W, et al. Variable effects of explosive or gradual increase of intracranial pressure on myocardial structure and function. Circulation I993;87(I):230-9.
6. D'Amico TA, Meyers CH, Koutlas TC, et al. Desensitization of myocardial betaadrenergic receptors and deterioration of left ventricular function after brain death. JThorac Cardiovasc Surg 1995;IIO(3):746-5I.

7. Wheeldon DR, Potter CD, Oduro A, et al. Transforming the "unacceptable" donor: outcomes from the adoption of a standardized donor management technique. $J$ Heart Lung Transplant 1995;I4(4):734-42.

8. Richardson DW, Robinson AG. Desmopressin. Ann Intern Med I985;103(2):228-39.

9. Totsuka E, Dodson F, Urakami A, et al. Influence of high donor serum sodium levels on early postoperative graft function in human liver transplantation: effect of correction of donor hypernatremia. Liver Transpl Surg I999;5(5):42I-8.

Io. Rosendale JD, Kauffman HM, McBride MA, et al. Hormonal resuscitation associated with more transplanted organs with no sacrifice in survival. Transplantation 2004;78(2) suppl I:I7.

II. Follette DM, Rudich SM, Babcock WD. Improved oxygenation and increased lung donor recovery with high-dose steroid administration after brain death. J Heart Lung Transplant I998; $17(4): 423-9$.

I2. Hunt SA, Baldwin J, Baumgartner W, et al. Cardiovascular management of a potential heart donor: a statement from the Transplantation Committee of the American College of Cardiology. Crit Care Med i996;24(9):1599-6or.

13. McGiffin DC, Savunen T, Kirklin JK, et al. A multivariable analysis of pretransplantation risk factors for disease development and morbid events. J Thorac Cardiovasc Surg 1995;109(6):I08I-9.

I4. Zaroff JG, Rosengard BR, Armstrong WF, et al. Consensus conference report maximizing use of organs recovered from the cadaver donor: cardiac recommendations. Circulation 2002;106(7):836-4I.

I5. Ventilation with lower tidal volumes as compared with traditional tidal volumes for acute lung injury and the acute respiratory distress syndrome. The Acute Respiratory Distress Syndrome Network. N Engl J Med 2000;342(I8):I30I-8.

16. Cells, tissues, and organs for transplantation and assisted reproduction: general requirements (Z900.I-03). Mississauga: Canadian Standards Association; 2003.

I7. Rodriguez I, Fluiters E, Perez-Mendez LF, et al. Factors associated with mortality of patients with myxoedema coma: prospective study in II cases treated in a single institution. J Endocrinol 2004; $180(2): 347-50$.

I8. Schwartz GJ, Brion LP, Spitzer A. The use of plasma creatinine concentration for estimating glomerular filtration rate in infants, children, and adolescents. Pediatr Clin North Am 1987;34(3):571-90.

I9. Mathers LH, Frankel LR. Stabilization of the critically ill child. In Behrman RE,Kliegman RM,Jenson HB (editors). Nelson textbook of pediatrics (I7th ed.). Philadelphia: Saunders; 2004

20. About knowledge transfer. Ottawa: Canadian Institutes of Health Research; 2005 Available: www.cihr-irsc.gc.ca/e/294I8.html (accessed I Dec. 2005).

Correspondence to: Dr. Sam D. Shemie, Division of Pediatric Critical Care, Montreal Children's Hospital, McGill University Health Centre, Montréal, QC $\mathrm{H}_{3} \mathrm{H}_{1} P_{3}$; sam.shemie@muhc.mcgill.ca

Reprint requests to: Ms. Kimberly Young, Canadian Council for Donation and Transplantation, 1702-8215 II2 Street, Edmonton $A B$ T6G 2C8; 780 409-5652; kimberly.young@ccdt.ca 
Forum participants concluded that there are significant limitations to existing clinical research in support of forum recommendations. Participants encouraged the development of local and multi-centre research initiatives, as well as those at national and international levels. The following potential research topics were collected during small-group discussions.

Topics amenable to survey methods

- A cross-sectional survey examining current practice in the cardiopulmonary support of donors, including hemodynamic targets and supports, ventilation and lung recruitment strategies.

Topics amenable to observational studies

The following questions include survey methods, prospective and retrospective studies and database reviews:

- Contribution of serial echocardiography or dobutamine stress echocardiography to the evaluation of patients with reduced myocardial function compared with PAC alone

- Effect of radiographic contrast exposure (during cerebral angiography or coronary angiography) on renal graft function

- Investigation of the factors that contribute to variability of organ utilization rates between centres and correlation to post-transplant function

- Optimum vasopressor and inotrope combinations and the influence of delayed procurement on organ utilization

Topics amenable to non-randomized intervention studies

- Effect of serial lung recruitment maneuvers in organ donors on the $\mathrm{PaO}_{2} / \mathrm{FiO}_{2}$ ratio and lung procurement rates

- Pharmacologic studies of orally and intravenously administered $T_{4}$ and $T_{3}$ in humans, including kinetics, biological effects, optimum dosing, peripheral conversion times and effect of corticosteroids

Topics amenable to simple randomized controlled clinical trials

- Does combined hormonal therapy improve hemodynamics, organ function or organ utilization?

- Do PAC and goal-directed therapy improve hemodynamics, organ function or organ utilization?

- Evaluating the use of prophylactic $\mathrm{N}$-acetylcysteine to prevent constrast nephropathy and delayed graft function of deceased donor kidneys 
Optimizing donor management and organ utilization for transplantation requires widespread communication of the recommendations of this forum combined with broad engagement of individuals and organizations across the health system. To address these interdependent requirements, a Logistics and Knowledge Transfer (LKT) Group (see Appendix 4) met throughout the forum to address the question:

How can we ensure that the agreements developed at this forum are transferred into the field efficiently and effectively so that improvements in medical management occur as soon as possible?

Members of the LKT group developed recommendations to address both logistic and knowledge transfer challenges in relation to clinical practice and systemic change.

\section{Logistics challenges}

The LKT group discussed ways to facilitate the implementation of the guidelines (e.g., a standardized set of guidelines would promote clinical excellence and lead to the creation of constructive hospital policies) and factors that would hinder their implementation (e.g., consideration of resource implications for extended stays in the ICU, reduced organ recovery options due to lack of access to operating room time and a lack of a definition of what constitutes an organ procurement hospital). They made the following recommendations to address the logistic issues that might hinder implementation of the guidelines:

- Prepare a cost-benefit analysis of donation, including implications for the health care system and quality-of-life issues.

- Monitor and report on the resolution of logistic challenges on an individual case basis with respect to their impact on optimum organ utilization.

\section{Knowledge transfer challenges}

The Canadian Institutes of Health Research (CIHR) describe knowledge transfer as the process that transfers research results from knowledge producers to knowledge users for the benefit of Canadians. ${ }^{20}$ It comprises three interlinked components:

- Knowledge exchange

- Knowledge synthesis

- Ethically sound application of knowledge.

The goal of knowledge transfer is to improve health processes, services and products as well as the health care system itself. Members of the LKT group made the following recommendations (alphabetical order) to maximize knowledge transfer and enhance organ utilization:

- Develop policies to guide the donation process that clearly identify roles and responsibilities for health care professionals (e.g., incorporation of the recommendations of this forum into standard operating procedures at organ procurement organizations and hospitals).

- Encourage national and international exchange of information to advance knowledge and care within and beyond Canada.

- Ensure that allocation issues do not complicate utilization, resulting in unused organs.

- Include the identification of potential organ and tissue donors as part of high-quality end-of-life care to maximize organ utilization.

- Provide health care professionals with ongoing education and skill development in support of high-quality care for donors and their families. Develop quick reference tools for protocols and guidelines.

- Support the implementation of the forum's recommendations in organizations and institutions affiliated with the forum.

- Support initiatives to enhance reporting and accountability. Encourage standardization of data and terminology both nationally and internationally. Develop high-quality measurements that reflect directly on the donation process, including identification of donors, requests for consent, giving consent and utilization of organs. 


\section{Appendix 3: Standing orders for management of organ donors}

It is important to take the necessary time in the ICU to optimize multi-organ function to improve transplant outcomes. Resuscitation and re-evaluation can improve reversible organ dysfunction (myocardial and cardiovascular dysfunction, oxygenation impairment related to potentially reversible lung injury, invasive bacterial infections, hypernatremia) and evaluate temporal trends in hepatic aspartate aminotransferase (AST), alanine aminotransferase (ALT) and creatinine or any other potentially treatable situation. This treatment period can range from 12 to $24 \mathrm{~h}$ and should be accompanied by frequent re-evaluation to demonstrate improvement in organ function toward defined targets. Once organ function is optimized, surgical procurement procedures should be arranged emergently.

There are no demographic factors or organ dysfunction thresholds that preclude giving consent for donation and offering organs for transplantation.

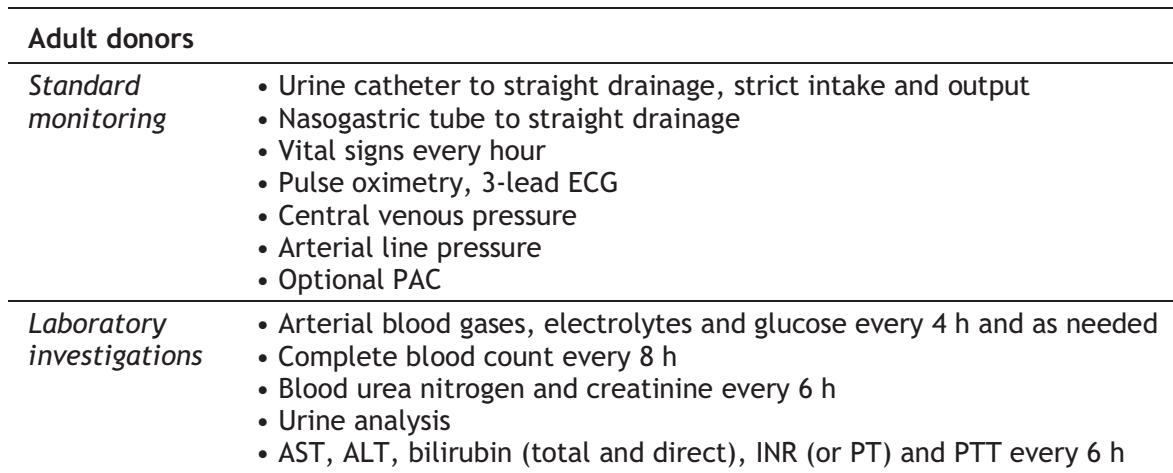

Hemodynamic General targets: heart rate $60-120 \mathrm{bpm}$, systolic blood pressure $>100 \mathrm{~mm} \mathrm{Hg}$, mean arterial pressure $\geq 70 \mathrm{~mm} \mathrm{Hg}$ monitoring - Fluid resuscitation to maintain normovolemia, central venous pressure $6-10 \mathrm{~mm} \mathrm{Hg}$

and therapy - If arterial blood pressure $\geq 160 / 90 \mathrm{~mm} \mathrm{Hg}$, then: Wean inotropes and vasopressors and, if necessary, start

- Nitroprusside: $0.5-5.0 \mu \mathrm{g} / \mathrm{kg}$ per minute or

- Esmolol: $100-500 \mu \mathrm{g} / \mathrm{kg}$ bolus followed by $100-300 \mu \mathrm{g} / \mathrm{kg}$ per minute

- Serum lactate every $2-4 \mathrm{~h}$

- Mixed venous oximetry every $2-4 \mathrm{~h}$; titrate therapy to $\mathrm{MVO}_{2} \geq 60 \%$

Agents for

hemodynamic • Vasopressin: $\leq 2.4 \mathrm{U} / \mathrm{h}(0.04 \mathrm{U} /$ minute $)$

support - Norepinephrine, epinephrine, phenylephrine (caution with doses $>0.2 \mu \mathrm{g} / \mathrm{kg} / \mathrm{minute}$ )

Indications for $\quad$ 2-dimensional echo ejection fraction $\leq 40 \%$ and/or

PAC

- Dopamine $>10 \mu \mathrm{g} / \mathrm{kg}$ per minute (or equivalent) and/or

- Vasopressor support (not including vasopressin if part of hormone therapy) and/or

- Escalation of supports

Glycemia and $\quad$ Routine intravenous dextrose infusions

nutrition $\quad$ Initiate or continue enteral feeding as tolerated

- Continue parenteral nutrition if already initiated

- Initiate and titrate insulin infusion to maintain serum glucose level at 4-8 mmol/L

Fluid and $\quad$ Urine output $0.5-3 \mathrm{~mL} / \mathrm{kg}$ per $\mathrm{h}$

electrolyte $\quad$ Serum Na 130-150 mM

targets - Normal ranges for potassium, calcium, magnesium, phosphate

Diabetes Defined as:

insipidus - Urine ouptut $>4 \mathrm{~mL} / \mathrm{kg}$ per $\mathrm{h}$ associated with

- Rising serum sodium $\geq 145 \mathrm{mmol} / \mathrm{L}$ and/or

- Rising serum osmolarity $\geq 300 \mathrm{mos}$ and/or

- Decreasing urine osmolarity $\leq 200 \operatorname{mos} M$

Therapy (to be titrated to urine output $\leq 3 \mathrm{~mL} / \mathrm{kg}$ per h):

- Intravenous vasopressin infusion at $\leq 2.4 \mathrm{U} / \mathrm{h}$ and/or

- Intermittent DDAVP, 1-4 $\mu \mathrm{g}$ IV then 1-2 $\mu \mathrm{g}$ IV every $6 \mathrm{~h}$ (there is no true upper limit for dose; should be titrated to desired urine output rate)

Combined

hormonal

therapy

\section{Defined as:}

- Tetraiodothyronine (T4) : $20 \mu \mathrm{g}$ IV bolus followed by $10 \mu \mathrm{g} / \mathrm{h}$ IV infusion (or $100 \mu \mathrm{g}$ IV bolus followed by $50 \mu \mathrm{g}$ IV every 12h)

- Vasopressin: $1 \mathrm{U}$ IV bolus followed by $2.4 \mathrm{U} / \mathrm{h}$ IV infusion

- Methylprednisolone: $15 \mathrm{mg} / \mathrm{kg}(\leq 1 \mathrm{~g})$ IV every $24 \mathrm{~h}$

Indications:

- 2-dimensional echocardiographic ejection fraction $\leq 40 \%$ or

- Hemodynamic instability (includes shock, unresponsive to restoration of normovolemia and requiring vasoactive support [dopamine $>10 \mu \mathrm{g} /$ minute or any vasopressor agent])

- Consideration should be given to its use in all donors 


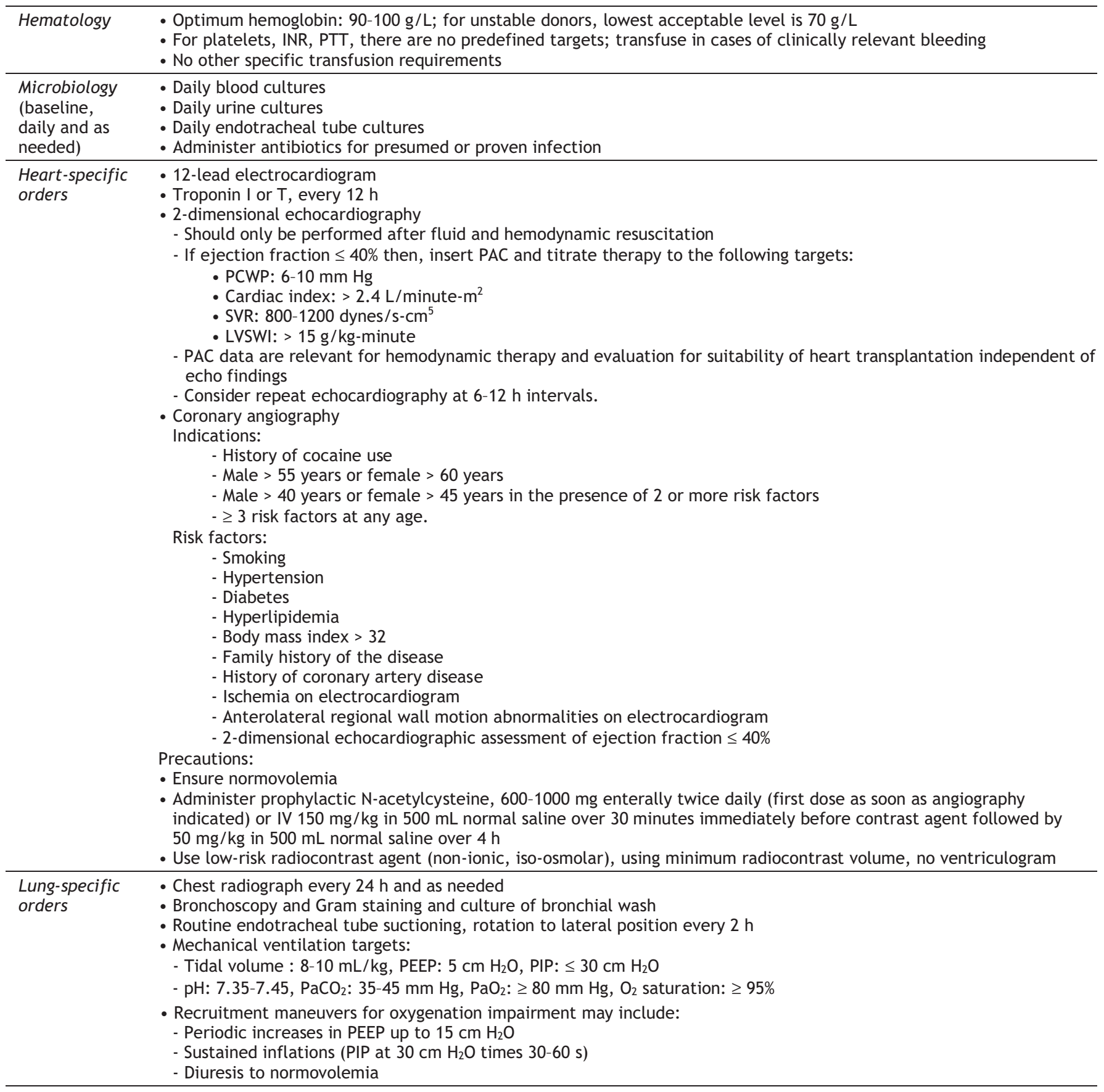

\section{Pediatric organ donors}

These orders apply to newborns to 18 year olds and are intended for care provided within a pediatric ICU. Dose recommendations apply to children $\leq 60 \mathrm{~kg}$; for children $>60 \mathrm{~kg}$, adult dosing should apply.

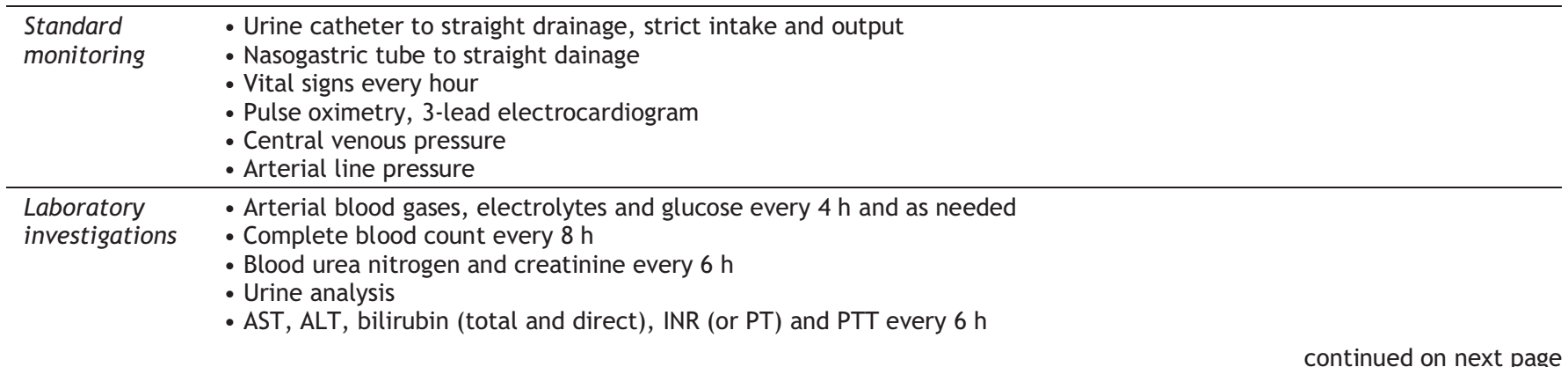


Hemodynamic General targets: Age-related norms for pulse and blood pressure

monitoring - Fluid resuscitation to maintain normovolemia, central venous pressure 6-10 $\mathrm{mm} \mathrm{Hg}$

and therapy - Age-related treatment thresholds for arterial hypertension:

Newborns - 3 months $\quad>90 / 60 \mathrm{~mm} \mathrm{Hg}$

$>3-12$ months $\quad>110 / 70 \mathrm{~mm} \mathrm{Hg}$

$1-12$ years $\quad>130 / 80 \mathrm{~mm} \mathrm{Hg}$

$>12-18$ years $\quad>140 / 90 \mathrm{~mm} \mathrm{Hg}$

- Wean inotropes and vasopressors and, if necessary, start

- nitroprusside: $0.5-5.0 \mu \mathrm{g} / \mathrm{kg}$ per minute or

- esmolol: $100-500 \mu \mathrm{g} / \mathrm{kg}$ bolus followed by $100-300 \mu \mathrm{g} / \mathrm{kg}$ per minute

- Serum lactate every 2-4 h

- Central venous oximetry every $2-4$ h: titrate therapy to central venous oxygen saturation of $\geq 60 \%$

Agents for

hemodynamic

support

Glycemia and

nutrition

- Dopamine: $\leq 10 \mu \mathrm{g} / \mathrm{kg}$ per minute

- Vasopressin: 0.0003-0.0007 U/kg per minute $(0.3-0.7 \mathrm{mU} / \mathrm{kg} /$ minute) to a maximum dose of $2.4 \mathrm{U} / \mathrm{h}$

- Norepinephrine, epinephrine, phenylephrine (caution with doses $>0.2 \mu \mathrm{g} / \mathrm{kg}$ per minute)

- Routine intravenous dextrose infusions

- Initiate or continue enteral feeding as tolerated

- Continue parenteral nutrition if already initiated

- Initiate and titrate insulin infusion to maintain serum glucose level at 4-8 mmol/L

\begin{tabular}{ll}
\hline Fluid and & - Urine output: $0.5-3 \mathrm{~mL} / \mathrm{kg}$ per $\mathrm{h}$ \\
electrolyte & - Serum sodium: $130-150 \mathrm{mM}$ \\
targets & - Normal ranges for potassium, calcium, magnesium, phosphate \\
\hline
\end{tabular}

Diabetes

insipidus $\quad$ Urine output $>4 \mathrm{~mL} / \mathrm{kg}$ per $\mathrm{h}$ associated with

- Rising serum sodium $\geq 145 \mathrm{mmol} / \mathrm{L}$ and/or

- Rising serum osmolarity $\geq 300$ mosM and/or

- Decreasing urine osmolarity $\leq 200 \operatorname{mos} M$

Therapy (to be titrated to urine output $\leq 3 \mathrm{~mL} / \mathrm{kg}$ per h):

- Intravenous vasopressin infusion: $0.0003-0.0007 \mathrm{U} / \mathrm{kg}$ per minute $(0.3-0.7 \mathrm{mU} / \mathrm{kg}$ per minute) to a maximum dose of $2.4 \mathrm{U} / \mathrm{h}$ and/or

- Intermittent DDAVP: $0.25-1 \mu \mathrm{g}$ IV every $6 \mathrm{~h}$ (there is no true upper limit for dose; should be titrated to desired urine output rate)

Combined Defined as:

hormonal $\quad$ Tetraiodothyronine (T4): $20 \mu \mathrm{g}$ IV bolus followed by $10 \mu \mathrm{g} / \mathrm{h}$ IV infusion (or 50-100 $\mu \mathrm{g}$ IV bolus followed by $25-50 \mu \mathrm{g}$ IV

therapy every $12 \mathrm{~h}$ )

- Vasopressin: 0.0003-0.0007 U/kg/minute $(0.3-0.7 \mathrm{mU} / \mathrm{kg}$ per minute) to a maximum dose of $2.4 \mathrm{U} / \mathrm{h}$

- Methylprednisolone: $15 \mathrm{mg} / \mathrm{kg}(\leq 1 \mathrm{~g})$ IV every $24 \mathrm{~h}$

Indications:

- 2-dimensional echocardiographic assessment of ejection fraction $\leq 40 \%$ or

- Hemodynamic instability (includes shock, unresponsive to restoration of normovolemia and requiring vasoactive

support [dopamine $>10 \mu \mathrm{g} /$ minute or any vasopressor agent])

- Consideration should be given to its use in all donors

Hematology - Optimum hemoglobin: $90-100 \mathrm{~g} / \mathrm{L}$; for unstable donors, lowest acceptable level is $70 \mathrm{~g} / \mathrm{L}$

- For platelets, INR, PTT, there are no predefined targets; transfuse in cases of clinically relevant bleeding

- No other specific transfusion requirements.

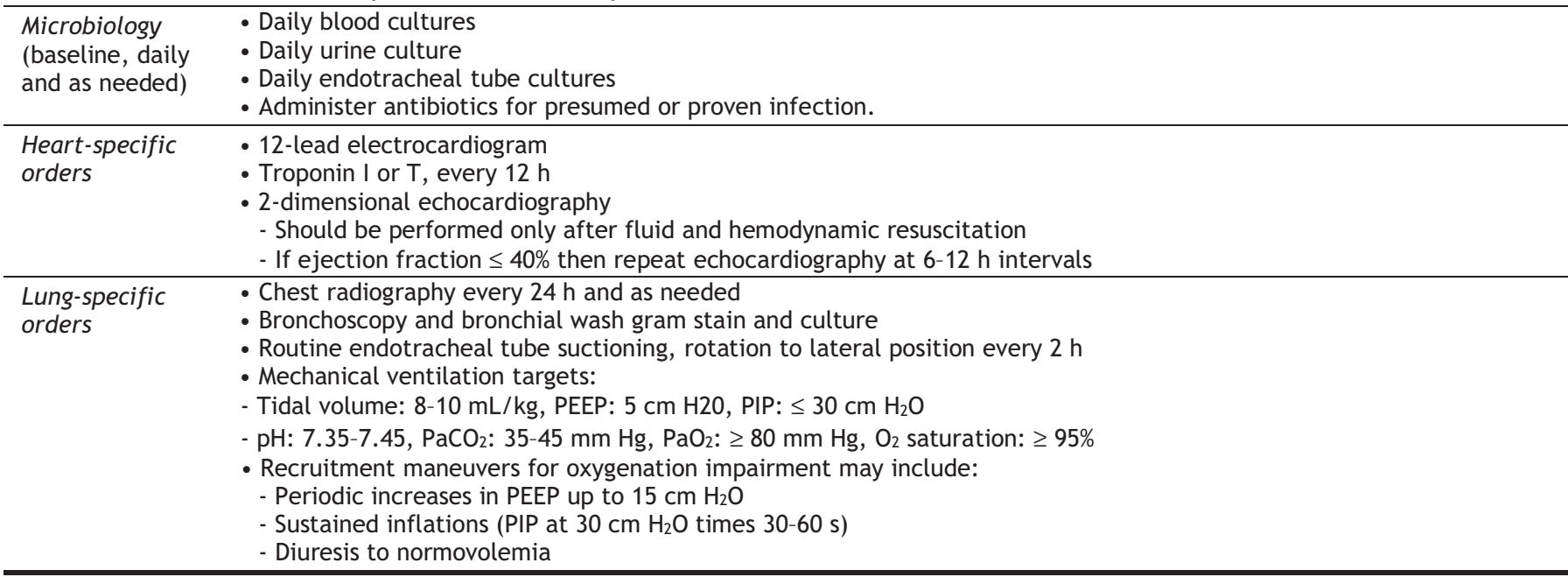




\section{Appendix 4: Forum participants}

Expert speakers: Expert speakers provided detailed presentations that were instrumental in the development of the recommendations in this report. They are listed in the order in which they appeared on the agenda.

\section{Multisystem management of multi-organ donors}

Dr. Sam D. Shemie Challenge address, Division of Pediatric Critical Care, Montreal Children's Hospital, McGill, University Health Centre, Montréal, Que., and Honorary staff Department of Critical Care Medicine, Hospital for Sick Children, University of Toronto, Toronto, Ont., and Canadian Council for Donation and Transplantation, Canadian Critical Care Society; Dr. Joe Pagliarello, Fundamentals of ICU-based donor management, Medical Director, Adult Critical Care, Organ and Tissue Donation Program, The Ottawa Hospital, University of Ottawa, Ottawa, Ont., and President-Elect, Canadian Critical Care Society; Mr. Kevin O'Connor, U.S. perspectives on donor management, Director of Donation Services, New England Organ Bank, Newton, Mass.; Dr. Bruce Rosengard, International perspectives on donor management: from Crystal City to Papworth, Professor and chair, Cardiothoracic Surgery Surgical Unit, Papworth Hospital, University of Cambridge, Cambridge, United Kingdom, and International Society for Heart and Lung Transplantation, American Society of Transplantation, British Heart Foundation; Dr. Dimitri Novitzky, The scientific rationale for hormonal therapy in the organ donor, Chief, Clinical Research, James A. Haley Veterans Hospital, Professor of Cardiothoracic Surgery, University of South Florida, Tampa, Fla.; Dr. Myron Kauffman, Hormonal therapy and the impact on transplantability in the USA, Kidney Transplantation, United Network for Organ Sharing, Richmond, Va.;

\section{Organ-specific considerations: hearts, lungs and intra-abdominal organs}

Dr. Vivek Rao Organ-specific panel heart, Surgical Director, Cardiac Transplant, University Health Network, University of Toronto, Toronto, Ont., and Canadian Society of Transplantation; Dr. Shaf Keshavjee Organ-specific panel lungs, Director, Toronto Lung Transplant Program, University Health Network, University of Toronto, Toronto, Ont., and Canadian Society of Transplantation; Dr. Paul Greig Organ-specific panel liver, Director, GI Transplant Program, Toronto General Hospital, University of, Toronto, Toronto, Ont., and Canadian Transplantation Society, Canadian Organ Replacement Register; Dr. Sandra Cockfield Organ-specific panel kidneys, Medical Director, Kidney Transplant Program University of Alberta, Hospital, University of Alberta, Edmonton, Alta., and Canadian Society of Transplantation;

\section{Other systemic challenges}

Ms. Kim Badovinac, Organ utilization from Canadian cadaveric donors: Canadian Organ Replacement Registry data, Consultant, Canadian Institute for Health Information, Toronto, Ont., and Canadian Organ Replacement Registry; Dr. Heather Ross, Canadian multi-centre review of heart and lung utilization, Medical Director, Cardiac Transplant Program, University Health Network, Toronto, Ont., and President, Canadian Society of Transplantation;

\section{Forum Recommendations Group}

Dr. Andrew Baker, Medical Director, Trauma and Neurosurgery ICU, St. Michael's Hospital, University of Toronto, Toronto, Ont., and Chair, Clinical Advisory Committee, Trillium, Gift of Life Network, Canadian Critical Care Society, Canadian Anesthesiologists' Society; Ms. Tracy Brand, Provincial Program Manager, Saskatchewan Transplant Program, Saskatoon, Sask., and President, Canadian Association of Transplantation; Dr. Christopher Doig, Multisystems Intensive Care Unit, Foothills Hospital, Department of Critical Care, University of Calgary , Calgary, Alta., and Chair, Donation Committee, Canadian Council for Donation and Transplantation, Canadian Critical Care Society; Dr. Paul Greig, Director, GI Transplant Program, Toronto General Hospital, University of, Toronto, Toronto, Ont., and Canadian Transplantation Society, and Canadian Organ Replacement Register; Dr. Cameron Guest, Department of Critical Care Medicine, Sunnybrook and Women's College, Health Sciences Centre, University of Toronto, Toronto, Ont., and Chief Medical Officer, Trillium Gift of Life Network, Canadian Critical Care Society; Dr. Shaf Keshavjee, Director, Toronto Lung Transplant Program, University Health Network, University of Toronto, Toronto, Ont., and Canadian Society of Transplantation; Dr. Peter Nickerson, Director Immunogenetics Laboratory, Canadian Blood Services, Health, Sciences Centre, University of Manitoba, Winnipeg, Man., and Canadian Society of Transplantation; Dr. Joe Pagliarello, Medical Director, Adult Critical Care, Organ and Tissue Donation Program, The Ottawa Hospital, University of Ottawa, Ottawa, Ont., and President-Elect, Canadian Critical Care Society; Dr. Vivek Rao, Surgical Director, Cardiac Transplant Program, University Health Network, University of Toronto, Toronto, Ont., and Canadian Society of Transplantation; Dr. Heather Ross, Medical Director, Cardiac Transplant Program, University Health Network, University of Toronto, Toronto, Ont., and President, Canadian Society of Transplantation; Dr. Sam D. Shemie, Division of Pediatric Critical Care, Montreal Children's Hospital, McGill, University Health Centre, Montréal, Que., and Honorary staff, Department of Critical Care Medicine, Hospital for Sick Children, University of Toronto, Toronto, Ont., and Canadian Council for Donation and Transplantation, and Canadian Critical Care Society; Ms. Kimberly Young, Senior Policy Analyst, Canadian Council for Donation and Transplantation, Secretariat, Health Canada, Edmonton, Alta., and Forum Project Manager, Medical Management to Optimize Donor Organ Potential;

Pediatric Recommendations Group

Dr. Mary Bennett, Resident Training Director, Pediatric Critical Care, British Columbia, Children's Hospital, University of British Columbia, Vancouver, BC, and Canadian Critical Care Society; Dr. David Creery, Director, Pediatric Intensive Care Unit, Children's Hospital of Eastern, Ontario, University of Ottawa, Ottawa, Ont., and Canadian Critical Care Society; Dr. Anne Dipchand, Clinical Head, Heart Transplant Program, The Hospital for Sick Children, University of Toronto, Toronto, Ont., and Canadian Society of Transplantation; Dr. Catherine Farrell, Pediatric Intensivist, Chair, Organ Donation Committee, Division of Pediatric, Intensive Care, Hôpital Sainte-Justine, Université de Montréal, Montréal, Que., and Canadian Critical Care Society; Dr. Diane Hébert, Clinical Director, Pediatric Multi-organ Transplant Program, Hospital for, Sick Children, University of Toronto, Toronto, Ont., and Canadian Society of Transplantation; Ms. Karen Hornby, Critical Care Nurse and Research Coordinator, Pediatric Intensive Care Unit, Montreal Children's Hospital, McGill University Health Centre, Montréal, Que., and Canadian Association of Critical Care Nurses; Dr. Michel Lallier, Surgical Director, Transplantation, Hôpital Sainte-Justine, University of Montreal, Montréal, Que., and Canadian Society of Transplantation; Dr. Sam D. Shemie, Division of Pediatric Critical Care, Montreal Children's Hospital, McGill, University Health Centre, Montréal, Que., and Honorary staff, Department of Critical Care Medicine, Hospital for Sick Children, University of Toronto, Toronto, Ont., and Canadian Council for Donation and Transplantation, and Canadian 
Critical Care Society; Dr. Lori West, Section Head, Heart Transplant Program, The Hospital for Sick Children, University of Toronto, Toronto, Ont., and Canadian Society of Transplantation; Ms. Kimberly Young, Senior Policy Analyst, Canadian Council for Donation and Transplantation, Secretariat, Health Canada, Edmonton, Alta., and Forum Project Manager, Medical Management to Optimize Donor Organ Potential

\section{Logistics and Knowledge Transfer Group}

Deborah Gordon (Chair), Senior Operating Officer, Capital Health, University of Alberta Hospital, Edmonton, Alta.; Ms. Kim Badovinac, Consultant, Canadian Institute for Health Information, Toronto, Ont., and Canadian Organ Replacement Registry; Mr. Bill Barrable, Provincial Executive Director, British Columbia Transplant Society \&, Research Institute, Vancouver, BC; Ms. Mance Cléroux, Executive Director, Québec-Transplant, Montréal, Que., and Canadian Association for Transplantation; Mr. Thorsten Duebel, Acting Director, Canadian Council for Donation and Transplantation, Secretariat, Edmonton, Alta.; Ms. Nora Johnston, Project Team Leader, Alberta Health and Wellness, Edmonton, Alta.; Mr. Darwin Kealey, President and CEO, Trillium Gift of Life Network, Toronto, Ont.; Ms. Joyce MacMullen, Health Service Manager, Critical Care/Organ Donation Coordinators, QE II, Health Sciences Centre, Halifax, NS, and Canadian Association of Critical Care Nurses; Mr. Burton Mattice, Vice-President/Chief Operating Officer, Carolina Donor Services, Durham, NC, Chair, Association of Organ Procurement Organization Procurement Council; Ms. Ann Secord, Organ Procurement Officer, Health Services Branch, New Brunswick, Department of Health and Wellness, Fredericton, NB

\section{Other forum participants}

Dana Baran, Medical Director, Quebec-Transplant, Transplant Nephrology, McGill, University Health Centre, Montréal, Que., and Canadian Society of Transplantation; Jeffrey Barkun, Liver Transplantation, McGill University Health Centre, McGill University, Montréal, Que., and Canadian Society of Transplantation; Stephen Beed, Director of Critical Care, QE II Health Sciences Centre, Dalhousie, University, Halifax, NS, and Canadian Critical Care Society, and Canadian Anesthesiologists' Association; Karen Burns, London Health Sciences Centre, Victoria Hospital, Health Research, Methodology Program, McMaster University, Hamilton, Ont., and Canadian Critical Care Society, and Clinical Scholar in Critical Care; David Clarke, Department of Neurosurgery, QE II Health Sciences Centre, Halifax, N.S., and Canadian Neurosurgical Society; Rosemary Craen, Director of Neuroanesthesia, London Health Sciences Centre, University of Western Ontario, London, Ont., and Canadian Anesthesiologists' Society; Marc Deschenes, Medical Director, Liver Transplantation, McGill University Health Centre, Montréal, Que., and Canadian Society of Transplantation; Jan Emerton, Organ Donation Specialist, British Columbia Transplant Society, Vancouver, BC, and Canadian Association of Transplantation; David Forrest, Associate Director (locum), ICU, Vancouver General Hospital, Vancouver, BC, and Canadian Critical Care Society; Peter Goldberg, Director, Intensive Care Services, Royal Victoria Hospital, McGill, University Health Centre, Montréal, Que., and Canadian Critical Care Society; Peter Gorman, New Brunswick Organ and Tissue Procurement Program Steering Committee, Department of Neurosurgery, Southeast Regional Health, Authority, Moncton, NB; Mark Heule, Director of ICU, Misericordia Hospital, Edmonton, Alta., and Canadian Critical Care Society; Dan Howes, Kingston General Hospital, Queen's University, Kingston, Ont., and Canadian Association of Emergency Physicians; James Kutsogiannis, Physician Donation Leader, Capital Health, University of Alberta, Edmonton, Alta., and Canadian Critical Care Society; Stéphan Langevin, Hôpital de L'enfant-Jesus, Laval University, Québec, Que., and Canadian Critical Care Society, Quebec Intensivist Society; Joseph Lawen, Surgical Director, Kidney Transplant Program, QE II Health Science Centre, Halifax, NS, and Canadian Society of Transplantation; Neil Lazar, Site Director, Toronto General Hospital, Medical Surgical Intensive Care Unit, Adult Critical Care, University Health Network, University of Toronto, Toronto, Ont., and Canadian Critical Care Society; Michelle Leahey, Critical Care Donor Coordinator, QE II Health Sciences Centre, Halifax, N.S., and Canadian Association of Transplantation; MarieHélène LeBlanc, Medical Director, Heart Failure and Heart Transplantation, Hôpital Laval, Université Laval, Ste-Foy, Que., and Canadian Society of Transplantation; Dale Lien, Medical Director, Lung Transplant Program, University of Alberta Hospital, University of Alberta, Edmonton, Alta., and Canadian Society of Transplantation; Karen McRae, Director of Anesthesia for, Thoracic Surgery and Lung Transplantation, University Health Network, Toronto, Ont., and Canadian Anesthesiologists' Society; Joy Mintenko, Surgical ICU/Medical Pediatric ICU, Regina General Hospital, Regina, Sask., and Canadian Association of Critical Care Nurses; Terrance Myles, Canadian Neurosurgical Society, Interim Director, Division of Neurosurgery, University of Calgary Medical School Calgary, AB; Clare Payne, Canadian Association of Transplantation, Clinical Services Manager, Trillium Gift of Life Network, Toronto, Ont.; Sharon Peters, Canadian Critical Care Society, Adult Critical Care, Health Care Corporation of St. John's, St. John's, NL; Ann Secord, Organ Procurement Officer, Health Services Branch, New Brunswick Department of Health and Wellness, Fredericton, NB; Michael Sharpe, Canadian Critical Care Society, Adult Critical Care, London Health Sciences Centre, London, Ont.; Susan Shaw, Canadian Critical Care Society, Canadian Anesthesiologists' Society, Medical Director, ICU, Royal University Hospital, Saskatoon, SK; Ken Stewart, Canadian Society of Transplantation, Surgeon, Lung Transplantation, University of Alberta Hospital, Edmonton, AB; Bernard Tremblay, Canadian Association of Transplantation, Clinical Procurement Coordinator, Quebec-Transplant, Nurse Clinician - Organ and Tissue Donation, McGill University Health Centre, Montreal, PQ; Helmut Unruh, Canadian Society of Transplantation, Program Director, Manitoba Lung Transplant, University of Manitoba Health Sciences Centre, Winnipeg, MB; Corinne Weernink, President-Elect, Canadian Association of Transplantation, Transplant Donor Coordinator, London Health Sciences Centre, London, Ont.; Bryan Young, Canadian Neurocritical Care Group, Division of Neurology and Critical Care Medicine London Health Sciences Centre, London, Ont.

\section{Consultants}

Strachan-Tomlinson and Associates Ottawa, Ont.; Facilitation: Dorothy Strachan, Research: Paul Tomlinson; Project management team: Peter Ashley and Lisa Weiss 